\title{
The Role of Government Public Relations in Central Sulawesi Province: A Study Case of Information Disclosure on the 2018 Donggala Earthquake, Tsunami and Liquefaction
}

\author{
F K Mangun \\ Department of Communication Studies Universitas Indonesia, JakartaIndonesia \\ fatmala_kirana@yahoo.com
}

\begin{abstract}
This study describes the role of government public relations following the 2018 Donggala earthquake and liquefactionin Central Sulawesi Province. The researcher finds out about the role of public relations in Central Sulawesithrough Protocol and Public Relations Bureeau in effective disaster communication to the public. Article $28 \mathrm{~F}$ of the 1945 State Constitution of the Republic of Indonesia states that every person shall have the right to communicate and to obtain information. Thus, it is mandated by the law for the government to conduct public information disclosure, especiallyin critical condition. Data collected was through interviews and observations with informants. The findings of this study explain that the role of government PR in Central Sulawesi have been conducted in forms ofpress release through the Facebook account page as well as information through relevant WhatsApp groups.Generally, the role of government public relations in Central Sulawesi is relatively reactiveand relies on communication facilitators.
\end{abstract}

Keywords: Disaster Communication; Government Public Relations; Public Information Disclosure.

\section{Introduction}

Based on Central Sulawesi Provincial Regulation No. 8/2016 on the formation and arrangement of provincial and regional apparatus, Protocol and Public Relations Bureau is responsible of implementing policy, coordinating, monitoring, facilitating and conducting guidance on the practice of protocol for official visit, information gathering, publications and documentation.These activities also include coordinate with related government agencies and non-governmental institutions and communities. The Government of Central Sulawesi Province consists of district Secretary, Office, Agency and office. The Bureau is responsible to the regional secretary of Central Sulawesi Province. 


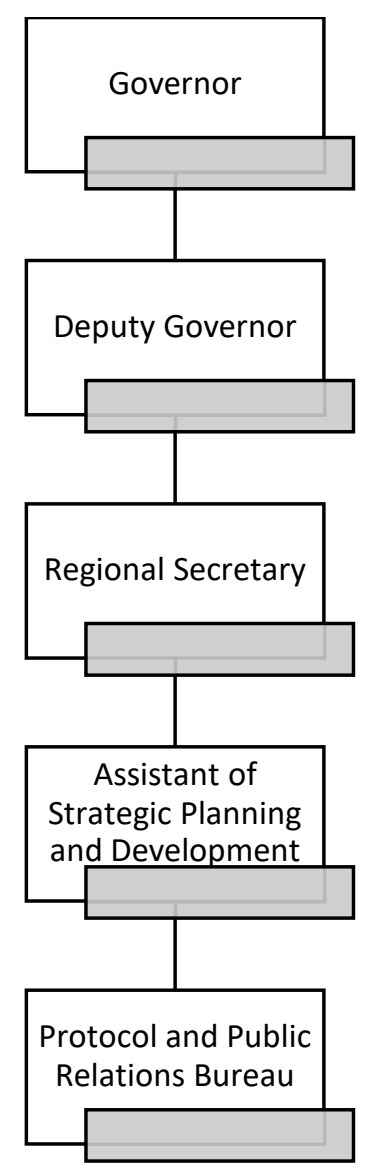

Fig.1. Organizational Structure of the Protocol and Public Relations Bureau of Central Sulawesi Province

The organizational structure implies the structural limitations for the Protocol and Public Relations Bureau to exercise the role of government PR. The Bureau is monitored by regional secretary, and the main responsibilities for communication technicians and facilitators. The role of the communication facilitator is beyond those routines and accentuate theboundary spanningfunction. Beechler, Levy, Taylor, \&Boyacigiller (2004) contend that "traditionally boundary spanning has been defined as the creation of team that integrate and coordinate across organizational boundaries."At this point, the role of PR is to serve public with communication functions in disseminating information.

For the purpose of this study, the researcher takes a case study of the 2018 disaster in assessing the role of the Bureau. On 28 September 2018, city of Palu, Sigi and Donggala Central Sulawesi was rocked 7.4 SR earthquake. This earthquake also resulted in a natural event in the form of a liquefaction phenomenon which was a sudden occurrence of land that could be caused by vibration of the earthquake. The liquefaction phenomenon sank many houses and took many lives in the Petobo area and Balaroa, Palu City(bbc.com, 2018) hundreds to thousands of lives were believed to be buried. 
As recorded by BNPB, reported from bbc.com (2018) the number of deaths caused by the disaster reached 2,073 people. Then, the damaged house amounted to 67,310 units (bbc.com, 2018). The significant impact caused by the earthquake disaster was the dissent of electricity and communication network that resulted in various kinds of logistics for survival, ranging from clean water, food, and medicine. Moreover, electricity and fuel oil wasincreasingly thinning. This had implications for the mass flow of exodus of citizens to move temporarily from Palu and other affected areas to safer locations.

In this post-disaster situation, the communication has stopped temporarily. It was because electricity was down.Next cause was the unsteady flow of transport. By these reasons, the crisis that occurred in this case was also a crisis based on the disbelief of the public against the government. The Government did not establish information quickly and responsively in the form of transmission of information about disasters.

Moreover, transparent communication from government and information disclosure was needed in critical circumstances. Piotrowski (2007) states that "Governmental transparency allows the public to develop a more accurate picture of what is happening in government, which allows citizens to hold governments accountable and evaluate performances of government agencies". Transparency becomes very essential to achieving an effective governmental relationship (Bertot\& Jaeger, 2010). Transparency defined as the availability of information about public problems and government obligations to pay attention to public opinion (Cotterrell, 1999).

Nowdays, issues of disclosure may be called transparency. Transparency involves the availability of organizational information to stakeholders. The more transparent of the organization, the more information stakeholders have about that organization and the easier their access to that information (Gower, 2006). Stakeholders may ask how transparent an organization is when it comes to crisis information (Coombs, 2014).

Along with information open, people can get the information of what they need. According to Cross \& Prusak (2002) "to be able to face the opportunities and challenges of the global world, PR needs to understand how to manage information that requires integrated networks". Referring to the legal basis of law 1945, article $28 \mathrm{~F}$ that "Everyone has the right to communicate and obtain information to develop their personal and social environment, and the right to seek, acquire, own and store information". The Law on public disclosure is Law No. 14/2008 which contains about "guarantee the right of citizens to know the making plan of public policy, public policy program, and public decision making process, as well as reasons for making a public decision".

Disaster communication is one of crucial things in dealing with disaster events. Although, compared to other aspects of crisis, communication in natural disasters has received less systematic attention (Seeger, Sellnow, \& Ulmer, 2003). Disaster communication should be done to encourage the spirit of victims, including those who remain to survive in the disaster (Susanto, 2011). Disaster communication is also conducted as an effort to convey true and accurate information and from credible sources so that it can be fully trusted by the society. Disaster communication is not only done when post-disaster, but also a pre-disaster as what the society has to do when natural disasters occur. On the other hand, it also needs to be considered as an early warning before a disaster occurs so that public first gets a warning before a disaster occurs, which can minimize the victim (Harjadi, 2007).

As the running of time, post-disaster events are increasingly complex. The government struggles with post-disaster progress such as direct government assistance, temporary residence, permanent residence, reconstruction of buildings, and other infrastructure development. This requires a proactive process of PR related to the activities that the 
government is doing in cities, provinces, and centers. Therefore, the researcher wants to know and understand how the government PR's role of the district of Central Sulawesi in the condition of a disaster and liquefaction? Does the Government and PR have done disclosure of information to the public, as well as any communication media?

\section{Research Method}

The method in this study used a qualitative method which was interpreted as "inductive research". The researcher generally used this method to explore meaning and insight in certain situations "(Strauss \& Corbin, 2008; Levitt, et al., 2017). The analytical dimensions of this study involved in-depth interviews and observations. The paradigm used was interpretive paradigm, namely a paradigm that sees social reality as something dynamic, not separated from each other, proceeds and full of subjective meaning (Patton, 1990). Based on the interpretive paradigms approach that aimed to find out the meaning of a social relationship, then qualitative method was needed to look for in depth data.

The data used primary data which collected through interviews and observations. Researcher observed the field in temporary residence, to see the circumstances. This observation was made when interviewing informants affected by disasters. The interview consisted of two informants. The first informant was the government PR of Central Sulawesi initials as HR and the second informant were victims of the aftermath in Petobo were initials as IK, an informant that was an academic in one of the state university in Palu City. The researcher chose government PR of Central Sulawesi as an informant to explore information about the role of PR both conventionally and digitally. The selection of the second informant was an affected victim to understand how communications were received from the government, through any media, as well as to observe directly in the field of the residential assistance. This study also used secondary data, that was from the literature, internet browsing and previous studies.

\section{Results And Discussion}

The interviews were conducted on two informants. After the interview, the researcher get results about the disclosure of information from government PR of Central Sulawesi, as well as disclosure of information from the viewpoint of disaster affected victims. Application of information disclosure of government activities of Central Sulawesi related to the role in transparency that is through media including cooperation with online media, Whatsapp, and Facebok. Previously, government PR of Central Sulawesi tends to use conventional techniquesby simply documenting data, it is sufficiently stored as an archive requirement. However, after a disaster on September 2018, PR begins to pursue his role in digital PR realm.

Relating to the role of government PR which tends to prepare material of publication and documentation, manuscript drafting, and holding activities and formal meetings, the role and function are still at the level of contribution as facilitator and communication technician. It has not yet reached the stage of decision-making with the Government as an expert prescriber. The role of government PR of Central Sulawesi as a communication facilitator, presented by Broom and Dozier (Theaker, 2001) in which PR interpretedand opened two-way communication between the organization and its public. 
In addition, government PR of Central Sulawesi also has a role as a communication technician supported by Broom and Dozier statements that in the implementation of PR programs and activities by using technical skills such as writing. PR plays a role as technician and does not perform the research function and is not involved in the decision making process. Moreover, the disclosure of information from the victim affected by the disaster is still limited to gather the information from Whatsapp group chat rooms. The society is gaining more direct information from the urban village and neighbourhood related to disaster social assistance. The flow of information obtained as a whole, can be said to still be at the level of conventionaland not yet optimally utilize digital media.

\subsection{Government Public Relations in the Digital Era}

Public relations has been interpreted as "government public relations is the type of communication function that deals with the interaction of the citizenry with the Government, with governmental regulators, and the legislative and regulatory arms of Government. Government public relations helps to facilitate communication with constituencies and with governmental publics" (Bowen, 2011). Cutlip\& Center (2006) explain that public relation has a definition as a management function that builds and maintains the good and beneficial relationships between organizations and the public.

According to the interview with the informant, there are several government PR roles of Central Sulawesi in the digital era, especially related to the delivery of post-disaster information. "If the general information such as the activity of Mr. Governor, consolidation with external parties, and implementation of the program, previously we documented and saved as a regional archive" (HR)

It can be said that the government PR's role is still at the conventional level namely documenting the program for archiving. Meanwhile, after disaster, PR begins to use digital in the delivery of information. ".. Since the disaster happened, I am as PR with the team, often use online media. We convey the information through WhatsApp. In WhatsApp I form a group with ASN and there is also a group with local journalists to disseminate information related to government and post-disaster management."(HR)

Relating to the role of PR, it has also done cooperation with other online media and news portals to disseminate post-disaster information. ".. Yes certainly there. We also cooperate with local news portals such as the info of Palu City and the Central Sulawesi Province lately. "(HR)

According to the informant, government PR of Central Sulawesi has been carrying out the role of PR by using digital media as a media of communication with the society, as well as cooperation with online media.

\subsection{Information Disclosure}

In Indonesia, the disclosure of information on public information has also been governed by the law of RI Number 14 Year 2008 on public disclosure of information consisting of 64 Article. Thus, it can be seen that the disclosure of information from the Government or formal institutions to the public becomes very important and crucial, considering that it is regulated in the law.Communication about the government in the digital age has been transformed towards the use of social media (Bertot, Jaeger, Munson, \&Glaisyer, 2010). Social media makes government PR practitioners develop their ability to seek information and find out relevant inputs and opinions from the public (Hand \& Ching, 2011). A recent study on social media by 
Wright and Hinson (2010) finds the results that the professional PR believes that social media tools bring many benefits.

Through interviews with key informant, information disclosure has been sought to be conducted in response to post-disaster. ".. I think we have communicated well to the society. About social assistance of post-disaster and management, we have many effort and we convey to the society through ASN and online media. We think the information provided is open ".(HR)

When viewed from the point of view of the second informant as an affected victim, the information obtained by many sources from the urban village. "For the information, we get from urban village and downgrades to the neighbourhood chairman of the WhatsApp group. In WA group there is news about the disaster that we can get. The information is usually about social assistance or about constraints. But usually if you want to ask for certainty from the government, we immediately come to the urban village ".(IK)

Social Media used as two-way dialogue between government organizations and their public to negotiated exchange of ideas and opinions(Kent \& Taylor, 1998). This two-way communication is a PR to the role of disclosure of information. "We have sought as much as possible from the Government to communicate the things that need to be related to the impact of disaster and its appearance" (HR)

According to the second informant that is IK, the society has gained information from the Government through the group of WhatsApp according to each area of neighbourhood. "Early after the disaster we often receive the food from the government. Then, in WhatsApp group there is a basic groceries, so we take it in the house of neighbourhoodchairman. When we move to temporary residence, there is just a lot of help".(IK) "We provide information through the press release on my personal Facebook. I think it is enough and I hope it reaches the society of Central Sulawesi". (HR)

Some forms of press releases are made and posted on social media Facebook in private accounts government PR of Central Sulawesi, as the following:

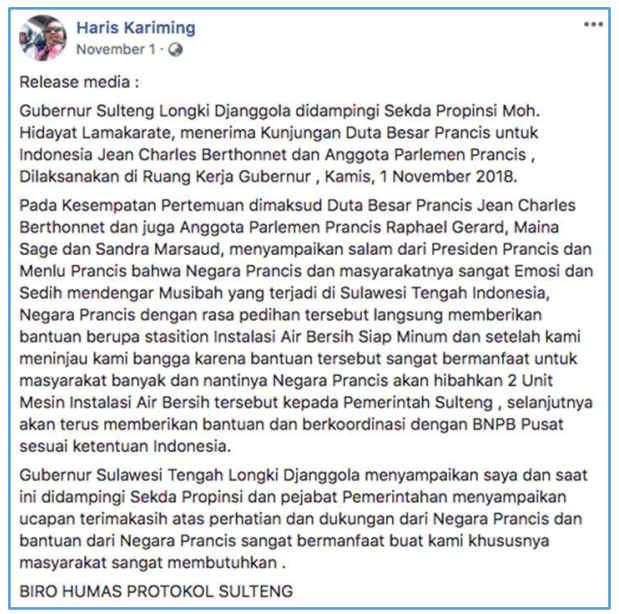

Fig.2. Press Release acceptance of visits by provincial Government 


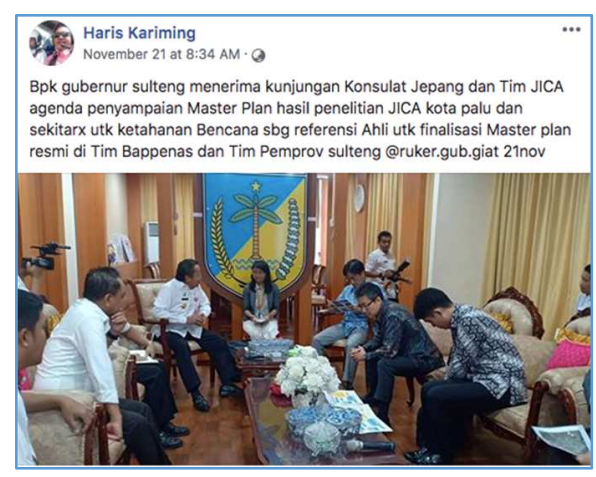

Fig.3. Documentation of reception visit

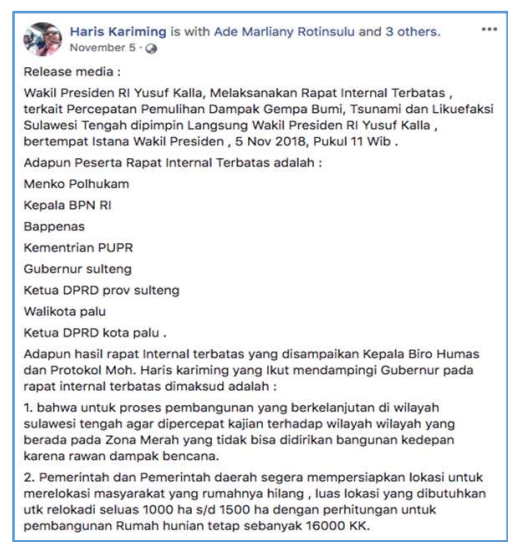

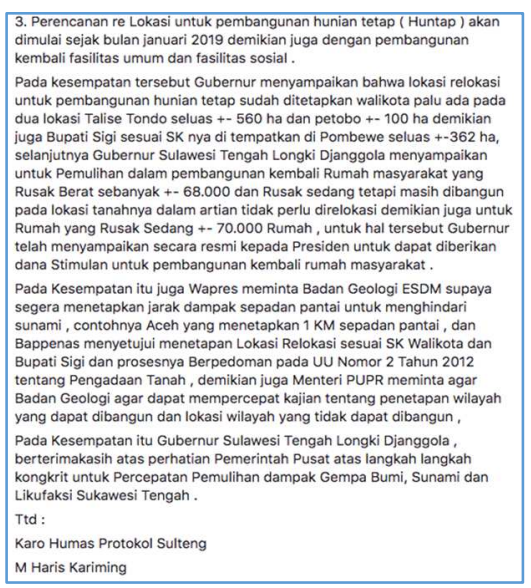

Fig.4. Press Release Limited Internal meeting 


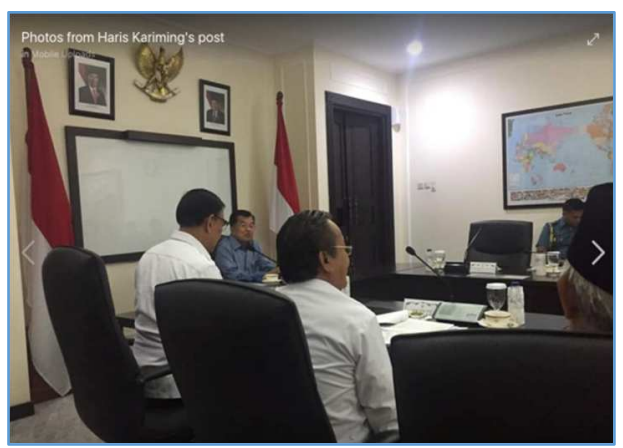

Fig.5. Limited Internal Meeting

Source: Facebook of HarisKariming, 2018

\subsection{Disaster Communication}

Through communication that is guided to the ethics of communication in delivering the message, from one source to each to obtain understanding, then communication becomes very essential when natural disasters happened (Susanto, 2011). It is certainly not easy to organize integrative disaster messages with mutual understanding of government agencies, private sector, and the wider society.

Rogers (Susanto, 2011) suggests that "the modernization of communication technologies to be more important, although more difficult to implement". According to Boos, Koolstra and Willems (Priest, 2010) that exposure to mass media can affect public opinion. "We are certainly responding and addressing the issues of disaster management. We respond immediately. By doing press release on Facebook, also we immediately responded the whatsapp group with ASN and reporters "(HR)

The government PR of Central Sulawesi performed a reactive task as it begins to react after a stimulus in the form of issues. Bachtiar (2007) in the implementation of disaster management, government must prepare a disaster management that includes analysis of disaster prone areas, identification of potential and source systems, as well as determining policies and steps in the event of a disaster, then communicating them to the society. "Yes, these steps we have already traveled, we review slowly". (HR)

According to the informant, government PR of Central Sulawesi has carried out many progress from post-disaster conditions to the present. "So, the progress has many stages. First we review it in the field. Then, we prepare what is needed, after which we execute both directly, as well as through the help of social service personnel. Then, we communicate directly the output to the society" (HR) "The policy that we do from the beginning of the disaster until today is still going on. Although there are technical problems that make us a little delayed, but this has been undertaken with maximum ". (HR)

It can be seen that government PR of Central Sulawesi continues to seek disaster communication continuously, through the steps that are not simple because it requires integration from various parties. "..the policies about the handling of post-disaster are also deployed to the City area. Thus, from the Province, we give more rights to the affected city areas in handling the impact of disasters such as temporary shelter programs, permanent residences, and other assistance"(HR) 


\section{Conclusions}

Government PR of Central Sulawesi runs its role as a communication facilitator, not yet touching the policy formulation. The use of social and digital media has become a way for Government PR in conducting information disclosure in the post disaster conditions. However, the use of digital media has not been fully maximized. The Government PR of Central Sulawesi is still in the level of PR that conduct one-way communication. In facing the PRcrisis the government of Central Sulawesi is also doing the reactive stage and not yet proactive.PR can also conduct surveys to assess performance of PR that can be disseminated through social media.Maintaining the website by updating news. Here, PR can check information about government policies, activities, and programs of the Government. Arranging proactive programs for Central Sulawesi policies to avoid the emergence of negative issues and communication crises. The program arranged can be a meeting aimed at two-way communication between government and its public to support the disclosure of information to the public.

\section{References}

[1] Beechler, dkk.: Part A: Boundary Spannign As a Global Management Competency. Blackwell Publishing, 121-133 (2004)

[2] Bertot, J.C., Jaeger, P., Munson, S., \&Glaisyer, T.: Social media technology and government transparency. IEEE Computer Society, November issue (2010)

[3] Bowen, Shannon. A.: Ethics in Government Public Relations. University of South Carolina (2011)

[4] Cutlip, Center \& Broom.: Effective Public Relations. Jakarta: Kencana (2009)

[5] Cotterrell, R.: Transparency, mass media, ideology and community. Cultural Values, 3(4), 414426 (1999)

[6] Cross, R. \&Prusak, L.: The people who make organizations go-or stop. Harvard Business Review, 80(6), 104-112 (2002)

[7] Dixon, B.: Towards e-government 2.0: An assessment of where e-government 2.0 is and where it is headed. Public Administration and Management, 15, 418-454 (2010)

[8] Hand, L.C. \& Ching, B.D.: You have one friend request: An exploration of power and citizen engagement in local governments' use of social media. Administrative Theory and Praxis, 33, 362-382 (2011)

[9] Kaplan, A. \&Haenlein, M.: Users of the world, unite! The challenges and opportunities of social media. Business Horizons, 53, 59-68 (2010)

[10] Kent, M.L. \& Taylor, M.: Building dialogic relationships through the World Wide Web. Public Relations Review, 24, 321-334 (1998)

[11] Levitt, H. M., Motulsky, S. L., Wertz, F. J., Morrow, S. L., \&Ponterotto, J. G. Recommendations for Designing and Reviewing Qualitative Research in Psychology: Promoting Methodological Integrity. Qualitative Psychology, 4(1), 2-22 (2017)

[12] Patton. M.Q.: Qualitative Evaluation and Research Methods. London, New Delhi: Sage Publications. (1990)

[13] Piotrowski, S. J.: Governmental transparency in the path of administrative reform. Albany, NY: State University of New York Press (2007)

[14] Priest, Susanna Hornig.: Science Comunication. Manhattan: Sage Publication (2010)

[15] PrihHarjadi, PJ.: Bahaya dan UpayaPenanggulanganBencana Tsunami. Jakarta: Badan Meteorologi dan Geofisika (BMG) (2007) 
[16] Seeger, M. W., Sellnow, T. L., \& Ulmer, R. R.: Communication and organizational crisis. Wesport, CT: Praeger Publishers (2003)

[17] SultengTerkini.: RibuanWarga Demo TurunkanWalikota dan Wakil WalikotaPalu. Dilansirdarihttps://sultengterkini.com/2018/10/19/ribuan-warga-demo-turunkan-walikota-danwakil-walikota-palu/ pada 29 Oktober 2018 (2018)

[18] Strauss, A., \& Corbin, J.: Basics of Qualitative Research: Techniques and Procedures for Developing Grounded Theory (3rd Ed.). Thousand Oaks, London, New Delhi: SAGE Publications (2008)

[19] Susanto, Eko Harr.: KomunikasiBencana. Yogyakarta: Asosiasi Pendidikan Tinggi IlmuKomunikasi (ASPIKOM) (2011) 